\title{
On the Development of Xi'an Intelligent Logistics Based on "Three Economy"
}

\author{
Duan Zheng \\ Department of Logistics Management, Xi'an International University, Xi'an, China
}

Keywords: Intelligent Logistics; Logistics Service Network; Logistics Informatization; Three Economy.

Abstract: This paper takes the development of intelligent logistics in Xi'an as the research object. On the basis of summarizing the concepts, functions, characteristics and functions of intelligent logistics, it discusses the current situation of the development of intelligent logistics in Xi'an in detail, and analyses the existing problems in the development of intelligent logistics in Xi'an. The causes of these problems mainly lie in the lack of early implementation of planning and the lack of management of intelligent logistics. It can effectively implement, the exchange of relevant information is not smooth, and the ability of intelligent logistics staff is insufficient. Finally, it puts forward the Countermeasures for the development of intelligent logistics in Xi'an from four aspects: formulating an integrated logistics service network, establishing and perfecting the intelligent logistics management system, improving the level of intelligent logistics informationization, and improving the business ability and professional quality of intelligent logistics talents, so as to make Xi'an wise logistics develop. Logistics can develop better and faster, and also provide some reference for the development of other cities'intelligent logistics.

\section{Introduction}

After the small-scale, low-efficiency and high-cost development in the 1950s to the large-scale, industrialization and the emergence of third-party logistics in the 1990s, the logistics industry has become a comprehensive subject in terms of automation, intelligence, informatization and networking. And people's attention to logistics has gradually extended to the whole supply chain, just as in recent years, the key national support industry has changed from logistics industry to supply chain management. Logistics as the main driving force of supply chain, intelligent logistics as a new trend of logistics development, will inevitably bring earth-shaking changes to the logistics industry. The development of logistics industry in Xi'an has made remarkable achievements. The scale of logistics industry continues to grow, the logistics infrastructure system continues to improve, the scale of leading enterprises grows rapidly, and the logistics service capacity continues to improve, which provides an important support for the national economy and social development of the city. According to its important geographical position and superior transportation network, Xi'an has made many breakthroughs in the field of logistics, and the logistics development momentum is rapid. In 2017, Shaanxi Province proposed to build a modern economic system with "hub economy, portal economy and mobile economy" as its framework, focusing on promoting 
economic restructuring and industrial transformation and upgrading. Greater Xi'an undertakes the important mission of leading the development of the "three major economies". At the same time, Xi'an is in the critical period of building a trillion-grade modern service industry. In 2018, it was approved to build a national airport economic demonstration zone, which provides a new opportunity for concentrating on the development of the "three major economies". Accelerating the development of the "three economies" will not only bring about the rapid growth of the total demand for logistics services, but also further release the wise and customized demand for high-end logistics services, which will lead to the emergence of new logistics services, thus impelling the transformation, development and innovation of the logistics industry. The purpose and significance of this paper is to deeply study the realistic level and future development trend of the modern logistics industry in Xi'an, strive to improve the development level of the modern logistics industry in Xi'an, accelerate the implementation of the main body of the logistics market guidance project, and strive to enhance the radiation-driven role of leading enterprises, leading the innovation and development of the industry.

\section{The Theoretical Basis of Intelligent Logistics}

\subsection{Intelligent Logistics Concept}

Intelligent logistics refers to a modern logistics system based on the application of internet of things technology, which extends the internet to the physical world, integrates and innovates the internet and logistics entity network, realizes the state perception, real-time analysis and precise execution of logistics system, further achieves independent decision-making and learning enhancement, and possesses certain wisdom ability.

Intelligent logistics has the following three characteristics:

Interconnection and data-driven: all logistics elements are interconnected and interoperable, all business is digitized, and the whole process of logistics system is transparent and traceable; all data are business-oriented, and "data" is used to drive decision-making and implementation, enabling the logistics ecosystem.

Deep collaboration and efficient execution: deep collaboration across groups, enterprises and organizations, based on Intelligent Algorithm of global optimization of logistics system, dispatch the efficient division of labor and collaboration of all participants in the whole logistics system.

Independent decision-making, learning promotion: software definition logistics realizes independent decision-making, promotes the development of logistics system programmed control and automation; builds logistics brain through big data, cloud computing and artificial intelligence, makes decisions in perception, learns in execution, optimizes in learning, upgrades constantly in the actual operation of logistics, and improves learning.

\subsection{The Characteristic Development of Intelligent Logistics}

Table 1. Characteristic Transformation Diagram of Intelligent Logistics

\begin{tabular}{|c|c|c|}
\hline $\begin{array}{c}\text { The Present Characteristics } \\
\text { of Intelligent Logistics }\end{array}$ & $\begin{array}{c}\text { Future Characteristics of Intelligent } \\
\text { Logistics }\end{array}$ \\
\hline $\begin{array}{c}\text { 4P:Product,Price,Place,Prom } \\
\text { otion }\end{array}$ & $\begin{array}{c}\text { 4C:Customer Solution. } \\
\text { Cost,Convenience,Communication }\end{array}$ \\
\hline $\begin{array}{c}\text { 3R:Range,Response,Resolut } \\
\text { ion }\end{array}$ & 3V:Value, Visibility,Velocity \\
\cline { 3 - 3 } $\begin{array}{c}\text { VTT:Visibility,Traceability, } \\
\text { Transparency }\end{array}$ & EEE:Earth,Environment,Effect \\
\cline { 3 - 3 } & & \\
\hline
\end{tabular}


With the change of the market, the development of intelligent logistics presents several trends: 4P to 4C, 3R to 3V, VTT and EEE. These changes are customer-centered and market-driven.The characteristic transformation of intelligent logistics is shown in Table 1.

\section{Analysis of the Development Situation of Intelligent Logistics in Xi'an City}

\subsection{Intelligent Logistics Enterprise Number and Market Expansion}

The number of enterprises engaged in logistics business in Xi'an is increasing year by year. By the end of 2018, there are 30,000 enterprises registered to engage in logistics and related business. Among them, there are about 6,500 enterprises mainly engaged in logistics. The leading logistics enterprises with significant representation are Xi'an International Land Port Group and Shaanxi Province Logistics Group. In addition, the agglomeration effect of wisdom logistics in Xi'an is increasing. Express companies such as Zhongtong and Yuantong have invested more logistics projects in Xi'an and built many logistics service centers, which makes the market of wisdom logistics in Xi'an expand continuously.

\subsection{Relevant Policies have been Promulgated One after Another}

The development of intelligent logistics in Xi'an has been strongly supported by relevant policies, which provides a good social environment for the development of wisdom logistics. First of all, the "one belt and one road" economic development strategy put forward by China in 2013, in which $\mathrm{Xi}$ 'an, as an important node city of the strategic area along the way, has opened up new space for the development of intelligent logistics in Xi'an. Large enterprises at home and abroad have invested more resources in logistics and equipment in Xi'an. Beijing East will set up the global logistics headquarters in Xi'an, build the intelligent logistics industry base, build the intelligent supply chain warehousing network system, and the Silk Headquarters of Alibaba Group has also set up Xi'an, and the group's rookie network has invested 1 billion yuan in Xi'an. The introduction of intelligent logistics facilities such as fully automated assembly lines and robots is the West. The supporting facilities of Anzhi Logistics have been improved very well, which makes the demand for intelligent logistics services grow rapidly. In addition, the development of Xi'an Smart Logistics has been listed as a pilot city for innovative development of modern logistics in China on the basis of the explicit provisions of the Long-term Planning for the Development of Logistics Industry (20142020) and the Middle-term and Long-term Planning for the Development of Logistics Industry in Shaanxi Province (2015-2020). The Smart Logistics Industry Exposition in Xi'an has been held many times, and China's Smart Artifacts have been launched this year. Flow Innovation Partner Conference and so on, make Xi'an fully demonstrate the development status of intelligent logistics to the outside world, improve the social image and status of Xi'an intelligent logistics.

\subsection{The Network Data Information System has been Built Step by Step}

The development of intelligent logistics in Xi'an needs to rely on the full coverage of network and the establishment of network data information system. Firstly, the development of intelligent logistics can not be separated from the support of Internet of Things technology. There are only 40 large-scale logistics network enterprises in Xi'an, such as Xi'an Zhongxing Measurement and Control Co., Ltd. and Xi'an Chengfeng Science and Technology Co., Ltd., which mainly produce all kinds of logistics instruments and equipment related to intelligent logistics, and many enterprises have formed industry alliances of Internet of Things to promote enterprises. The construction of industrial logistics informationization has promoted the linkage innovation of Internet of Things model. At the same time, many famous universities, such as Xi'an University of Electronic Science and Technology and Xi'an University of Technology, have begun to actively develop network 
communication technology to achieve the greatest degree of intelligent development. They can effectively control all aspects of logistics activities by information technology, which makes the information level of intelligent logistics in Xi'an begin to have technical support. In addition, the development of smart logistics in Xi'an will build an Internet cloud logistics platform. In the future, both logistics enterprises and consumers can view the real-time status of logistics activities through the intelligent logistics service APP, realize the communication between online and offline smart logistics, optimize the logistics business process, improve the efficiency and effectiveness of logistics work, and make the smart logistics in Xi'an City. Services are more standardized and transparent. Independent decision-making, learning promotion: software definition logistics realizes independent decision-making, promotes the development of logistics system programmed control and automation; builds logistics brain through big data, cloud computing and artificial intelligence, makes decisions in perception, learns in execution, optimizes in learning, upgrades constantly in the actual operation of logistics, and improves learning.

\subsection{Developed Transportation Network}

The advantages of geographical location and transportation lay a solid hardware foundation for the development of intelligent logistics. First of all, Xi'an is the center of economic and cultural development in the Midwest of China, and is also an important node city in the strategic area. Therefore, the development of transportation in Xi'an is very important. In addition, the existing logistics and transportation infrastructure in Xi'an has been continuously improved. The freight terminal and freight area of Xianyang International Airport in Xi'an have begun to provide comprehensive services for air transport, which has increased the air cargo and postal throughput year by year and the air transport capacity. In the first half of 2017, the total passenger throughput increased by $14.4 \%$ compared with the same period last year. The construction of the new port city will greatly enhance the air transportation and logistics capacity of Xianyang International Airport in Xi'an. In August 2017, the planning of Xi'an Railway Hub was officially approved by China Railway Corporation, which will form a large ring-shaped radial railway hub connecting 11 directions and 15 trunk lines and Guanzhong Intercity Railway. It connects Baotou, Taiyuan, Wuhan, Zhengzhou and Chongqing in 11 directions; Baoxi, Daxi, Zhengxi, Xiwu, Xiyu, Xicheng, Xilan, Yinxi High-speed Railway, 15 main lines such as Longhai, Baoxi, Ningxi, Houxi, Xiantong Railway and the large-scale ring Radial Railway Hubs from Xi'an to Famensi, Hancheng and Tongguan. The Xi'an Railway Hub will form a three-level logistics node network of "1+2+4". Among them, the first-level logistics base will be newly built, the second-level logistics base will be opened through Queyang and Weinan, and the third-level logistics base will be established by Xi'an South (Yingzhen), Xinfeng Town and Airport (including EMU Express). Moreover, Xi'an's highway transportation network is more perfect, and the "Second Ring and Twelve Radiation" highway network is basically formed, which makes Xi'an become an important transportation hub connecting the eastern and western regions and communicating the northern and southern areas. Therefore, the integrated development of Xi'an's aviation, railway and highway logistics transportation network has become a safe, convenient and smooth three-dimensional integrated intelligent transportation system. The improvement of urban roads will help to reduce the transportation cost of regional logistics and promote the development of regional logistics.

\section{Analysis of Problems and Causes in the Development of Intelligent Logistics in Xi'an}

Xi'an intelligent logistics is still in its infancy. In the future, the intelligent logistics center in Northwest China will be built in Xi'an to serve the "one belt and one road", and a new generation of intelligent storage base with artificial intelligence and robots will be introduced. But there are still some problems in the process of development. 


\subsection{Imperfect Management System of Intelligent Logistics}

In the development of intelligent logistics in Xi'an, there is no corresponding laws and regulations. It is difficult to effectively supervise and manage some illegal and irregular problems in intelligent logistics, which makes the legal deterrence and effectiveness of intelligent logistics in Xi'an less effective. First of all, there is a lack of systematic and special legal provisions for the intelligent logistics in Xi'an. Because the intelligent logistics will involve many departments such as transportation department, industry and telecommunications department, and the intelligent logistics business is closely related to the transportation and information technology industries, but different departments have formulated different rules and management methods, which makes the development of the intelligent logistics multi-headed and decentralized. Institutional management leads to poor coordination and communication ability among departments and low level of logistics system management. In addition, the laws and regulations of Smart Logistics in Xi'an are lagging behind, and the content of the system is not constantly updated and improved with the development of the times and the actual needs of logistics enterprises. When problems arise in the cooperation between Smart Logistics and transportation and communication departments, it is difficult to provide effective institutional guarantee for the development of Smart Logistics.

\subsection{The Construction of Intelligent Logistics Information Platform can not Meet the Requirements}

Due to the problem of inconsistent standards in the construction of information platform, the relevant infrastructure can not run well. The intelligent logistics information platform among enterprises is not compatible and interoperable, which leads to the low degree of information resource sharing of intelligent logistics. Many logistics enterprises' intelligent information will not communicate with the logistics enterprises, which leads to the decline of logistics service quality. In addition, the intelligent function of the logistics information platform of some logistics enterprises in Xi'an is not perfect, the function of querying logistics vehicle positioning and tracking, logistics warehousing automation management and so on is poor, and even there may be technical network security problems, failing to achieve the integration of logistics, information flow and capital flow, for example, consumers in the logistics enterprise information platform order transaction, network payment. Information is stolen, causing serious economic property losses, which makes the logistics information platform of logistics enterprises need to be updated and upgraded.

\subsection{Insufficient Ability of Intelligent Logistics Staff}

In the development of Xi'an intelligent logistics, there is a lack of professional and excellent comprehensive and applied talents, which makes the advantages of intelligent logistics talents insufficient and the development level low. First of all, as a labor-intensive industry, the logistics industry in Xi'an needs a lot of logistics workers, but most of them can only carry out simple logistics operations, and high intelligent logistics talents are in short supply. Moreover, some logistics personnel are not aware of the importance of their own work, have low enthusiasm for improving their own intelligent logistics ability, and have poor application of modern information technology to carry out logistics work, which is easy to cause more work errors in the development of intelligent logistics, thus causing adverse impact on the development of intelligent logistics of logistics enterprises, even serious economic losses. 


\section{Countermeasures of Xi'an Intelligent Logistics Development Based on "Three Economy"}

\section{Develop an Integrated Logistics Service Network}

In the development of intelligent logistics in Xi'an, we should clarify the responsibilities of the government, strengthen the guiding role of the government, put forward preferential policies on the development of wisdom logistics, formulate an integrated logistics service network, coordinate the construction of logistics transportation infrastructure, optimize the spatial layout of wisdom logistics in Xi'an, and improve the development level of wisdom logistics in Xi'an. First of all, Xi'an municipal government should create a good social environment for the development of intelligent logistics. According to the actual situation of the logistics industry in Xi'an, it should increase the financial support in the aspect of intelligent logistics, actively introduce and focus on supporting the logistics enterprises with strong competitiveness, and provide policy subsidies or tax relief for the product R \& D and technical services of the logistics enterprises, and formulate scientific policies. The intelligent logistics evaluation system promotes the intelligent and information construction of logistics enterprises. In addition, in the development of Xi'an intelligent logistics, it is necessary to coordinate the construction of logistics transportation infrastructure, reasonably arrange logistics storage and distribution centers, strengthen the close cooperation between logistics and other industries, build several intelligent logistics parks, integrate various resources of intelligent logistics, so as to effectively optimize the development structure of intelligent logistics and promote the transformation and upgrading of intelligent logistics.

\subsection{Construction of Logistics Information Public Service Platform}

Relying on the big data of well-known enterprises such as ChuanHua, HNA, Jingdong, Alibaba China intelligent backbone network northwest core node, vipshop, Shaanxi logistics group, etc., Xi'an logistics big data center will be built in Xi'an international port area and Fengxi new city, focusing on promoting the relevant logistics data in the fields of road, railway, aviation, water transport, post and public security, industry and commerce, customs, quality inspection, etc. Open sharing, cross departmental, cross platform and cross regional connectivity and effective integration of logistics information. Through the cooperation between government and enterprises, Xi'an logistics information public service platform will be built, and the application functions of industry monitoring, information service, supply chain coordination, big data transaction will be strengthened, so as to realize the organic integration of government functions and business functions. Relying on the logistics big data center and logistics information public service platform, we will explore the construction of regional logistics elements trading platform, such as facilities, equipment, technology, and improve the ability of logistics resource integration. Support logistics enterprises to apply advanced information technology such as Internet, cloud computing, big data, etc., promote the Informatization Transformation of enterprise operation management system, promote the application of electronic documents such as electronic waybill, electronic warehouse receipt, electronic face-to-face list, and guide the digital development of logistics facilities, equipment and service products.

\subsection{Establish and Improve Intelligent Logistics Management System}

In the development of Xi'an intelligent logistics, it is necessary to keep up with the changing trend of the times and the actual needs of logistics enterprises, constantly update and improve the intelligent logistics management system, effectively restrict all aspects of intelligent logistics activities, and provide reliable system basis and guarantee for the development of intelligent logistics. First of all, different logistics enterprises in Xi'an should, according to their own development scale and characteristics, formulate corresponding rules and regulations of intelligent 
logistics, clarify the work content and responsibilities of intelligent logistics, strictly regulate the work process of intelligent logistics, and make the intelligent logistics work smoothly and orderly. In addition, in Xi'an intelligent logistics, it is necessary to strengthen the cooperation between logistics enterprises and transportation, communication and other departments, so it is necessary to develop a systematic and centralized intelligent logistics management system, promote the coordination and communication ability between departments, and make Xi'an intelligent logistics develop better and faster.

\subsection{Improve the Level of Intelligent Logistics Informatization}

In the development of Xi'an intelligent logistics, advanced information technologies such as Internet of things and cloud computing need to be used to improve the standards of intelligent logistics in the field of information through standardization, so as to improve the competitiveness of the whole Xi'an intelligent logistics in the future. Effectively integrate the information of all links of logistics activities, optimize intelligent logistics resources, improve the intelligent functions of intelligent logistics information platform, such as location tracking, order processing, etc., so that the government, logistics enterprises, shippers and consumers can use various platforms to realize the transmission and sharing of relevant data, which is conducive to improving the accuracy of intelligent logistics information and making the whole logistics operation higher. Effectiveness and convenience, improve the work efficiency of intelligent logistics, reduce logistics costs, and provide consumers with satisfactory integrated intelligent logistics information service.

\subsection{Accelerate the Training of Intelligent Logistics Talents}

Intelligent logistics is a high-tech work, which needs professional, excellent, high-level, highquality intelligent logistics talents to complete. Therefore, in the development of Xi'an intelligent logistics, it is urgent to cultivate the business ability and comprehensive quality of the staff, so as to give full play to the talent advantage in the intelligent logistics work and improve the quality of intelligent logistics work. First of all, in the teaching of logistics major in Xi'an institutions of higher learning, we should pay attention to strengthening the combination of students' theoretical knowledge and practical ability of logistics, encourage students to go deep into the logistics enterprise through the school enterprise cooperation mechanism, understand the intelligent logistics work more comprehensively and systematically, increase students' practical experience of intelligent logistics work, and lay a good foundation for participating in the intelligent logistics work after graduation. In addition, the logistics enterprises in Xi'an should actively introduce and cultivate logistics talents, improve the recruitment and assessment standards of logistics staff, improve the level of wages and benefits for logistics talents, so as to better retain logistics talents, and regularly organize excellent logistics talents for further study abroad or carry out intelligent logistics exchange meetings, so as to improve the quality of logistics talents in intelligent logistics work. R \& D capability and technological innovation to promote the healthy and sustainable development of Xi'an intelligent logistics.

\subsection{Accelerate the Development and Application of Advanced Logistics Technology and Equipment}

Give full play to Xi'an's scientific and technological innovation resources, strengthen cooperation with Jingdong, Anbo, Yuantong, Cainiao, ChuanHua and other enterprise groups, accelerate the research and development of logistics big data technology, logistics robot, automatic sorting equipment and other intelligent equipment, accelerate the industrialization of logistics technology and equipment, and improve the core competitiveness of the industry. We will accelerate the application of advanced technologies such as artificial intelligence, Internet of things, and containerization in the field of logistics, encourage logistics enterprises to upgrade their equipment, 
and improve the level of intelligence and modernization of logistics services. Formulate special policies to encourage logistics enterprises to increase the proportion of $\mathrm{R} \& \mathrm{D}$ investment, support enterprises to build their own R \& D centers or jointly build R \& D centers with universities and other scientific research institutions, and improve their technological innovation ability. We should strengthen the construction of science and technology innovation service system, encourage the development of various forms of innovation and entrepreneurship service platforms, strengthen technology transfer and transformation, entrepreneurship incubation and other services, and promote the transformation and application of scientific and technological achievements.

\section{Conclusion}

Xi'an will speed up the construction of intelligent logistics technical standards and specifications system, support the construction of new intelligent logistics park or the reconstruction and expansion of traditional logistics park, support the construction of Intelligent Logistics comprehensive management and service platform, intelligent warehousing and distribution system, intelligent terminal distribution network, etc., and improve the efficiency of warehousing, transportation, sorting, packaging and other operations. Relying on the construction of characteristic logistics towns such as "smart logistics town" and "yuncang town", build a smart logistics industry development demonstration zone integrating warehousing, distribution, settlement, big data, cloud computing, etc. Cooperate with JD to build the world's first low altitude UAV general aviation logistics network, and take Shaanxi as the center to radiate across the country. Promote the implementation of "Internet + efficient logistics", vigorously develop the "Internet +" vehicle matching, "Internet +" capacity optimization, "Internet +" transportation coordination, "Internet +" warehousing transaction, "Internet + " car free carrier, and other new formats and new modes to support the development of "Internet +" platform based logistics enterprises, promote the integration of logistics resources, and improve the whole supply chain service and integration. Service capability. With the implementation of these measures, Xi'an intelligent logistics will give new vitality under the guidance of the "three economies".

\section{References}

[1] X Yang R, Li B, Hu Y. An Experimental Study for Intelligent Logistics: A Middleware Approach[J]. Chinese Journal of Electronics, 2016, 25(3):561-569.

[2] LIU Hua. Research on theRole of Intelligent Logistics in Promoting the Supply Chain Ecosystem[J]. Journal of Beijing College of Finance and Commerce, 2018.(12): 24-25.

[3]Che Zhe. Research on the development strategy of intelligent logistics in China under the new strategy of "one belt and one road" [J]. logistics technology, 2016,39 (10): 112-114.

[4] Tan Hua, Lin Ke, Yang Shaolong, et al. Analysis of current development trend of intelligent logistics technology [J]. Mobile communication, 2016,40 (21): 45-49.

[5] Duan Shengxian, he Yanjun, bu Bei. Research on favorable conditions and policy guidance mechanism of intelligent logistics development in Changsha Zhuzhou Xiangtan area [J]. Logistics technology, 2016,35 (12): 6-9.

[6] Hao shuchi. Motivation and Countermeasures for the development of intelligent logistics [J]. Logistics technology, 2017,40 (1): 28-31. 